\title{
Evaluation of the topical spray containing Centella asiatica extract and its efficacy on excision wounds in rats
}

\author{
SOMCHAI SAWATDEE ${ }^{1,2, *}$ \\ KANUENGNIT CHOOCHUAY ${ }^{1,2}$ \\ WIROT CHANTHORN ${ }^{3}$ \\ TEERAPOL SRICHANA ${ }^{4}$ \\ ${ }^{1}$ School of Pharmacy, Walailak \\ University, Thasala District, Nakhon \\ Si Thammarat, 80161, Thailand \\ ${ }^{2}$ Drug and Cosmetic Research and \\ Development Unit, School of Pharmacy \\ Walailak University, Thasala District \\ Nakhon Si Thammarat, 80161, Thailand \\ ${ }^{3}$ Faculty of Public Health, Naresuan \\ University, Tha Pho, Muang \\ Phitsanulok, 65000, Thailand \\ ${ }^{4}$ Department of Pharmaceutical \\ Technology and Nanotec-PSU \\ Excellence Center on Drug Delivery \\ System, Faculty of Pharmaceutical \\ Sciences, Prince of Songkla University \\ Hat Yai, Songkhla 90112, Thailand \\ Accepted January 20, 2016 \\ Published online May 16, 2016
}

\begin{abstract}
Centella asiatica was extracted by methanol. The assay content of triterpenes in the extract was $0.12 \%$ asiatic acid, $0.54 \%$ madecassic acid, $0.25 \%$ asiaticoside and $1.02 \%$ madecassoside. The extract was complexed with hydroxypropyl- $\beta$-cyclodextrin (HP- $\beta$-CD) and formulated with Eudragit E100, glycerol, PEG 400, copovidone, ethanol and purified water. A clear yellowish solution (F1-F8) was obtained. The formulations had a $\mathrm{pH}$ of 5.5-6.0 with viscosity in the range of $20-60 \mathrm{mPa}$ s, surface tension $20.3-24.6$ $\mathrm{mN} \mathrm{m}^{-1}$ and contact angle less than $20^{\circ}$. The amount of PEG 400 and copovidone affected the film and spreadability. The content of triterpenes in the spray formulation was close to $100 \%$ compared to triterpenes in the extract. The skin irritation study indicated that the formulation was non-irritating in a rat model. An in vivo excision wound healing model showed that wound excision was completely healed after 14 days.
\end{abstract}

Keywords: Centella asiatica extract, hydroxypropyl- $\beta$-cyclodextrin, wound healing, topical spray

Centella asiatica (L.) belongs to the family Apiaceae (Umbeliferae) (Fig. 1). This herb is indigenous to the Indian subcontinent, Southeast Asia, and wetland regions of the Southeastern USA. It is a popular medicinal plant in several traditional medicines, especially in wound healing $(1,2)$. Based on numerous studies, the biologically active ingredients are believed to be triterpenes, namely, asiatic acid, madecassic acid, asiaticoside and madecassoside (3-5) (Fig. 2). Due to its ability to stimulate collagen synthesis, centella has been used in skin care products for restoring skin firmness, elasticity and improving skin appearance (3). The traditional claim of wound healing of $C$. asiatica extract as a cream, gel or solution has been well documented $(2,6,7)$. Topical spray solution is a dermatologic prod-

\footnotetext{
*Correspondence; e-mail: somchai086@hotmail.com, somchai.sa@wu.ac.th
} 


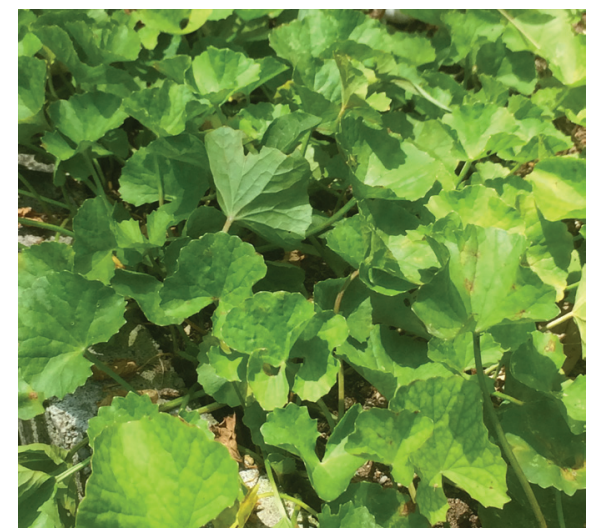

Fig. 1. Photograph of Centella asiatica (L.) collected from the Songkhla Province, Southern Thailand.

uct easily applied on the skin. C. asiatica extract preparation as a topical spray is suitable for the treatment of fresh wounds such as heat burns or other minor injuries like blade cuts, scratches, etc.

To enhance solubility and permeability of the extract, the inclusion complex of $C$. asiatica extract with cyclodextrin was investigated. C. asiatica extract contains water soluble compounds. Increasing the solubility of active ingredients may enhance the bioavailability of the product. Cyclodextrins are cyclic oligosaccharides with a hydrophilic outer surface and hydrophobic central cavity (8). Derivatives of cyclodextrin contain modified hydrophilic groups in order to increase cyclodextrin solubility. Hydroxypropyl- $\beta$-cyclodextrin $(\mathrm{HP}-\beta-\mathrm{CD})$ consists of seven glucopyranose units and is commonly used for enhancement of drug solubility (8-10). The HP- $\beta$-CD may increase extract solubility in the formulation by forming inclusion complexes with active compounds of centella extract. Cyclodextrins

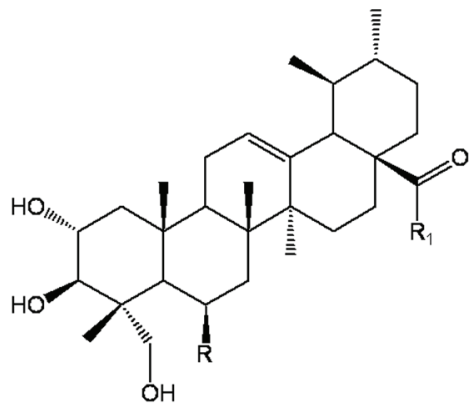

Asiatic Acid : $\mathrm{R}=\mathrm{H}, \mathrm{R}_{1}=\mathrm{OH}$

Madecassic Acid : $\mathrm{R}=\mathrm{OH}, \mathrm{R}_{1}=\mathrm{OH}$

Asiaticoside : $\mathrm{R}=\mathrm{H}, \mathrm{R}_{1}=\mathrm{O}$-Glu(6-1)-Glu(4-1)-Rham

Madecassoside : $\mathbf{R}=\mathrm{OH}, \mathbf{R}_{1}=\mathbf{O}$ - $\mathrm{Gu}(6-1)$-Glu(4-1)-Rham

Fig. 2. Chemical structure of the main active compounds of ursane-type triterpenes from Centella asiatica (L.). 
successfully increased solubility, which led to increased bioavailability of several acidic and basic drug compounds (11). Triterpenes have been reported to form inclusion complexes with HP- $\beta$-CD (12). The aim of this study was to determine the content of triterpenes in $C$. asiatica extract. We decided to prepare the inclusion complex of triterpene compounds by incorporating $\mathrm{HP}-\beta-\mathrm{CD}$ and to formulate it as a topical spray. The influence of excipients on the performance of the formulation was investigated. The formulations were evaluated for their physicochemical properties and stability. The efficacy with respect to a traditional claim of wound healing was tested in a rat model.

\section{EXPERIMENTAL}

\section{Materials}

Reference compounds of asiatic acid ( $\geq 97 \%)$ and madecassoside ( $\geq 95 \%)$ were obtained from Sigma-Aldrich Co. (St. Louis, USA). Madecassic acid ( $\geq 98 \%$ ) and asiaticoside ( $\geq 98 \%$ ) were obtained from Chengdu Biopurity Phytochemicals Ltd. (Chengdu, China), and Fluka Chemie $\mathrm{GmbH}$ (Switzerland), respectively. HP- $\beta$-CD was obtained from ISP Pharmaceuticals (Wayne, USA). Polyethylene glycol 400 (PEG 400) was procured from Srichand United Dispensary (Thailand). Eudragit ${ }^{\circledR}$ E100 (amino methacrylate copolymer) was obtained from Evonik (Germany). Kolidon ${ }^{\circledR}$ VA 64 (copovidone) was obtained from BASF (Germany). Glycerine was supplied by the P.C. Drug Center (Thailand). Ethanol (absolute) was obtained from V.S. Chem. House (Thailand). Petroleum ether (boiling point $60{ }^{\circ} \mathrm{C}$ ) and methanol were purchased from RCI Labscan (Thailand). All other chemicals were of pharmaceutical grade and were used as received.

\section{Animal model}

Male Wistar rats, 150-200 g, were used in the study. All animals had free access to pelleted food and tap water ad libitum before the experiments. The animals were housed in clean polypropylene cages. Controlled room temperature $\left(25 \pm 2{ }^{\circ} \mathrm{C}\right)$ and humidity $(50-$ $60 \%$ ) were maintained, with a $12 \mathrm{~h}$ light and dark cycle, throughout the experiment.

\section{Plant material and extraction}

Whole parts of $C$. asiatica were collected following traditional practices of Thai herbalists from the Songkhla Province, Thailand. Specimens were identified and voucher specimens were deposited at the PSU Herbarium (Prince of Songkla University, Songkla, Thailand), Voucher No. SKP199030101. The aerial parts were cleaned with deionized water. The herb was extracted as described earlier (13). Briefly, air-dried aerial parts of C. asiatica were cut into tiny pieces, powdered with an automatic grinder, passed through 40 mesh sieves and stored in a closed vessel for future use. The powder was defatted with petroleum ether and extracted with methanol in a Soxhelet apparatus for $12 \mathrm{~h}$. The extraction process was carried out until the solvent appeared to be colorless. The extract was concentrated over a water bath $\left(50{ }^{\circ} \mathrm{C}\right)$ and dried at $50{ }^{\circ} \mathrm{C}\left( \pm 5^{\circ} \mathrm{C}\right)$ in a hot air oven under atmospheric conditions. Final traces of methanol were removed under reduced pressure $(\sim 8 \mathrm{mbar})$ at $55^{\circ} \mathrm{C}$ using a rotary evaporator. 


\section{Determination of triterpenes in C. asiatica extract}

Triterpenes in C. asiatica were analyzed by high performance liquid chromatography (HPLC) (3). Four triterpenes from C. asiatica extract were resolved using a gradient system (3). The triterpene reference compounds (asiatic acid, madecassic acid, asiaticoside, madecassoside) were prepared as a stock solution in methanol. Asiatic acid and madecassic acid stock solutions were diluted up to 6 different concentrations $\left(1-80 \mu \mathrm{g} \mathrm{mL}^{-1}\right)$ with methanol. Asiaticoside and madecassoside stock solutions were diluted up to 6 different concentrations (5-200 $\left.\mu \mathrm{g} \mathrm{mL}^{-1}\right)$ with methanol. The extract sample was dissolved in methanol $\left(1 \mathrm{mg} \mathrm{mL}^{-1}\right)$ and filtered through a $0.45 \mu \mathrm{m}$ nylon membrane syringe filter. The HPLC system (Waters, Milford, USA) consisted of a solvent delivery pump equipped with an inline degasser (Waters 1525 binary HPLC pump), a sample loop with an injection volume of $20 \mu \mathrm{L}$, and a Waters 2707 autosampler. Data were recorded using the Empower 2 software. Separations were performed on a reversed-phase stainless steel column (ACE 5 C18-AR; Advanced Chromatography Technologies, Aberdeen, Scotland) $(250 \mathrm{~mm}$ long $\times 4.6 \mathrm{~mm}$ internal diameter) filled with a $5 \mu \mathrm{m}$ octadecylsilane and maintained at $25^{\circ} \mathrm{C}$. The mobile phase used for the separation was $0.05 \%$ phosphoric acid (A) and acetonitrile (B). The flow rate was maintained at $1.0 \mathrm{~mL} \mathrm{~min}^{-1}$, and the separation was monitored by UV detection (Waters 2998 photodiode array detector) at a wavelength of $205 \mathrm{~nm}$.

\section{Formulation development}

Dried C. asiatica extract was employed to formulate a topical spray. The $2^{3}$ factorial designs were used to investigate the effects of three factors: PEG 400, copovidone and absolute ethanol to optimize the performance of the formulation (Table I). Each factor varied from a low to a high level. This made 8 formulations (F1-F8). The formulations were prepared as follows. One gram of dried C. asiatica extract and $2 \mathrm{~g}$ of HP- $\beta$-CD were first dispersed in $7 \mathrm{~mL}$ of purified water until a homogeneous mixture was obtained. Eudragit ${ }^{\circledast}$

Table I. The composition of Centella asiatica extract-HP- $\beta$-CD complexed topical spray formulation

\begin{tabular}{ccccccccc}
\hline & \multicolumn{7}{c}{ Ingredients $(\%, m / m)$} \\
\cline { 2 - 9 } $\begin{array}{c}\text { Formula- } \\
\text { tion }\end{array}$ & $\begin{array}{c}\text { Centella } \\
\text { asiatica } \\
\text { extract }\end{array}$ & HP- $\beta$-CD & $\begin{array}{c}\text { Eudragit } \\
\text { E100 }\end{array}$ & Glycerol & PEG400 & $\begin{array}{c}\text { Copovi- } \\
\text { done }\end{array}$ & Ethanol & $\begin{array}{c}\text { Purified } \\
\text { water }\end{array}$ \\
\hline F1 & 1 & 2 & 2 & 2 & 5 & 3 & 40 & 45 \\
F2 & 1 & 2 & 2 & 2 & 5 & 3 & 70 & 15 \\
F3 & 1 & 2 & 2 & 2 & 5 & 6 & 40 & 42 \\
F4 & 1 & 2 & 2 & 2 & 5 & 6 & 70 & 12 \\
F5 & 1 & 2 & 2 & 2 & 10 & 3 & 40 & 40 \\
F6 & 1 & 2 & 2 & 2 & 10 & 3 & 70 & 10 \\
F7 & 1 & 2 & 2 & 2 & 10 & 6 & 40 & 37 \\
F8 & 1 & 2 & 2 & 2 & 10 & 6 & 70 & 7 \\
\hline
\end{tabular}


E100 and copovidone were dissolved in absolute ethanol and then added to the suspension of $C$. asiatica extract complexed with $\mathrm{HP}-\beta-\mathrm{CD}$ and stirred at $300 \mathrm{rpm}$ until a clear solution was obtained. PEG 400 and glycerol were then added to the solution and stirred until a homogeneous mixture was obtained. The final concentration of $C$. asiatica extract in all formulation was $1 \%$. The effects of high and low levels of PEG 400, copovidone and ethanol on spreadability were evaluated along with evaporation time.

\section{Analysis of triterpenes in spray formulations}

One $\mathrm{mL}$ of each formulation (F1-F8) was transferred to a 10-mL volumetric flask and the volume was made up with methanol. The concentration of the extract prior to analysis was $1 \mathrm{mg} \mathrm{mL} \mathrm{m}^{-1}$. The samples were filtered through a $0.45 \mu \mathrm{m}$ nylon membrane prior to injection and triterpenes contents were analyzed by HPLC. The triterpene contents (asiatic acid, madecassic acid, asiaticoside, madecassoside) were reported as the percentage of the triterpenes found in the extract before the preparation according to Eq. (1):

$$
\text { Percentage of triterpene contents }=\frac{\text { Triterpenes in the topical spray }}{\text { Triterpenes in the extract }} \times 100
$$

\section{Physical evaluation of spray formulations}

Appearance. - Appearance of the topical spray products was evaluated by means of an organoleptic test such as clearness or transparency, spray adhesiveness on the skin, and formulation color.

$\mathrm{pH}$ value. - The $\mathrm{pH}$ of the formulations was determined using a digital $\mathrm{pH}$ meter (SevenEasy $^{\mathrm{TM}} \mathrm{pH}$, Mettler Toledo, Switzerland).

Viscosity. - Viscosity of C. asiatica extract topical spray was measured with a Brookfield Viscometer (model LV-DV-II, Helipatch-spindle type S-96, Germany).

Surface tension. - Surface tension was measured with a Contact Anglemeter OCA 15 EC using drop shape analysis. The angle meter released the solution through a small needle. The shape and form of the solution at the tip of the tube were recorded with a highresolution camera. The equipment recorded the shape and density of the droplets to calculate surface tension.

Contact angle. - The contact angle was measured using a Contact Anglemeter (OCA 15 EC, Dataphysics instruments $\mathrm{GmbH}$, Germany). The angle formed between the liquid/air interfaces is the contact angle. Pictures were taken incrementally as the droplet grew. The contact angle was always measured and referred to Young's equation as follows:

$$
\gamma_{\mathrm{sv}}=\gamma_{\mathrm{sl}}+\gamma_{\mathrm{lv}}(\cos \theta)
$$

where $\gamma_{\mathrm{sv}}, \gamma_{\mathrm{sl}}$ and $\gamma_{\mathrm{lv}}$ are interfacial tension of solid-vapor, solid-liquid and liquid-vapor $\left(\mathrm{mN} \mathrm{m}^{-1}\right)$, respectively, and $\theta$ is the contact angle $\left(0^{\circ}<\theta<180^{\circ}\right)(14)$. tion:

Spreadability, or spreading coefficient $(S)$, was calculated using the following equa- 


$$
\mathrm{S}=\gamma_{\mathrm{sv}}-\left(\gamma_{\mathrm{lv}}+\gamma_{\mathrm{sl}}\right)
$$

By substituting Young's equation (2) into equation (3):

$$
S=\gamma_{1 \mathrm{v}}(\cos \theta-1)
$$

Equation (4) was used to calculate the spreadability of the formulation.

Evaporation time. - The time needed for spray film to dry was estimated by spraying the formulation onto filter paper and the time taken for complete evaporation was recorded (15).

All the experiments were done in triplicates and the results are expressed as mean \pm SD.

\section{Stability study}

The products of $C$. asiatica-HP- $\beta$-CD complexed topical spray $(200 \mathrm{~mL}, n=10)$ were kept in a high density polyethylene (HDPE) spray bottle before the stability study. Stability studies were carried out at $30{ }^{\circ} \mathrm{C} / 75 \% \mathrm{RH}$ as a long-term condition. Evaluation parameters were appearance, assay of triterpene content, $\mathrm{pH}$ and viscosity at different time intervals over 6 months.

\section{Satisfaction survey}

The satisfaction survey included the appearance of the formulation (acceptance of color, odor, viscosity, willingness to use), dermal adhesion and water washability. This was tested on 5 volunteers. All volunteers were asked to evaluate the spray formulations and then grade their satisfaction in questionnaires. The questionnaire included 10 questions with a 5 score scale $(5=$ excellent, $4=$ very good, $3=$ good, $2=$ fair and $1=$ poor $)$ after using the spray for 3 days.

\section{Skin irritation study}

A preliminary skin irritation test was performed on male Wistar rats. The skin from the back of six rats was shaved off on both sides from the dorsal thoracic to the central region of anaesthetized rats. On cleaned test sides, 2 puffs $(\sim 1 \mathrm{~mL})$ of the prepared formulations (F1-F8) were applied and observed for the appearance of any irritation or erythema over a period of $72 \mathrm{~h}$ after the application of test preparations. Control formulations were applied on the other side of the prepared skin. All animal experiments were performed according to the Principles of laboratory animal care and were approved by the ethics committee.

\section{Evaluation of wound healing activity of spray formulations}

The animals were assigned into 3 groups ( $n=6$ in each group). Group 1 was untreated and was regarded as the control. Group 2 animals received povidone iodine solution (Betadine $^{\circledR}$ ) treatment, while group 3 animals received the $C$. asiatica extract topical spray (F1-F8). The excision wound model was conducted as follows. Animals were wounded 
under ether anesthesia aseptically. Full thickness from the marked area was excised to produce a wound measuring about $200 \mathrm{~mm}^{2}$. The wound was cleaned with a cotton swab soaked in alcohol. To the wounds of group 2 animals, povidone iodine solution, $10 \% \mathrm{~m} / \mathrm{V}$, was applied once daily for 14 days starting from the first day of wounding. To group $3 \mathrm{C}$ animals, asiatica extract-HP- $\beta$-CD complexed topical spray, 5 puffs $(\sim 2.5 \mathrm{~mL})$, was applied once daily by spraying the formulation from the spray bottle at a distance of $5 \mathrm{~cm}$ from the skin for 14 days starting from the first day of wounding. No other topical or systemic antibiotic therapy was given to animals in the course of the study. Wound contraction was measured at 2-14 days intervals.

\section{Statistical analysis}

All the experiments were performed in triplicate and the results are presented as mean \pm SD. Differences between experimental groups were compared by the one-way analysis of variance (ANOVA), followed by the least significant difference test (LSD). Significance was set as $p<0.05$.

\section{RESULTS AND DISCUSSION}

\section{Content of triterpenes in C. asiatica extract}

C. asiatica is known for its wound healing properties. Many active compounds were extracted from $C$. asiatica and triterpenes were especially reported $(3,16)$. Quantitative determination of triterpenes from $C$. asiatica by HPLC was previously reported $(3,16-19)$. The retention time in this study was 8 to $17 \mathrm{~min}$. The methanol extract yield was $5.80 \%$ $\mathrm{m} / \mathrm{m}$ with respect to the dry powdered plant material. The content of triterpenes in C. asiatica extract showed madecassoside $1.02 \pm 0.25$, madecassic acid $0.54 \pm 0.22$, asiaticoside 0.25 \pm 0.11 and asiatic acid $0.12 \pm 0.02 \%$ by dried plant mass.

\section{Formulation development of the spray}

Topical spray usually contains ethanol and water as solvents. Other excipients are cosolvent, which is used to dissolve the drug substance to obtain a clear solution, film forming agent and humectants. C. asiatica topical spray was developed by complexing $2 \%$ HP- $\beta$-CD with active triterpenes. Eudragit E100 was a film former with good adhesion. Copovidone was also an auxiliary film forming agent. Glycerol served as humectant and moisturizer. PEG 400 was used to promote moisture retention on the skin. All centella extract formulations (F1-F8) were clear and of light yellow color. The results are shown in Table II. The content of triterpene active compounds (asiatic acid, madecassic acid, asiaticoside, madecassoside) was within the range of 94-101\% compared to the content of triterpenes in the extract.

Normal pH skin values are reported within a broad range of 4.0 to $7.0(20,21)$. Woo et al. (2004) reported that the tissue $\mathrm{pH}$ in rats slightly decreased after skin was injured or incised (22). The decreasing $\mathrm{pH}$ of injured skin or slightly acidic $\mathrm{pH}$ after incision did not affect the formulation because the $\mathrm{pH}$ of the formulation was close to that of injured skin. In addition, although $\mathrm{pH}$ of acute or chronic wound skin had been recorded within the 
Table II. Content of triterpenes and stability results of the topical spray containing Centella asiatica extract complexed with HP- $\beta$-CD upon storage at $30^{\circ} \mathrm{C} / 75 \%$ RH for 6 months (mean $\pm S D, \mathrm{n}=6$ )

\begin{tabular}{|c|c|c|c|c|c|c|c|c|}
\hline \multirow{2}{*}{\multicolumn{2}{|c|}{$\begin{array}{c}\text { Formulation } \\
\text { and storage } \\
\text { duration }\end{array}$}} & \multicolumn{4}{|c|}{ Content of triterpenes ${ }^{\mathrm{a}}(\%)$} & \multirow[b]{2}{*}{ Appearance } & \multirow[b]{2}{*}{$\mathrm{pH}$} & \multirow{2}{*}{$\begin{array}{c}\text { Viscosity } \\
\text { (mPa s) }\end{array}$} \\
\hline & & Asiatic acid & $\begin{array}{l}\text { Madecassic } \\
\text { acid }\end{array}$ & Asiaticoside & $\begin{array}{l}\text { Madecasso- } \\
\text { side }\end{array}$ & & & \\
\hline \multirow[t]{2}{*}{ F1 } & initial & $98.12 \pm 2.18$ & & $94.23 \pm 1.67$ & & \multirow{2}{*}{$\begin{array}{c}\text { clear, slightly } \\
\text { yellow } \\
\text { solution }\end{array}$} & $5.5 \pm 0.00$ & $30 \pm 5$ \\
\hline & 6 months & $97.23 \pm 1.98$ & $96.12 \pm 0.02$ & $92.11 \pm 4.45$ & $94.28 \pm 3.22$ & & $5.8 \pm 0.00$ & $36 \pm 2$ \\
\hline \multirow[t]{2}{*}{$\mathrm{F} 2$} & initial & $97.11 \pm 3.45$ & $94.71 \pm 2.45$ & $95.18 \pm 1.54$ & $99.11 \pm 0.80$ & \multirow{2}{*}{$\begin{array}{c}\text { clear, slightly } \\
\text { yellow } \\
\text { solution }\end{array}$} & $5.5 \pm 0.02$ & $23 \pm 8$ \\
\hline & 6 months & $96.54 \pm 0.21$ & $94.33 \pm 1.10$ & $93.16 \pm 4.12$ & $98.77 \pm 0.66$ & & $5.8 \pm 0.01$ & $28 \pm 5$ \\
\hline \multirow[t]{2}{*}{ F3 } & initial & $94.54 \pm 1.03$ & $98.23 \pm 2.56$ & $95.24 \pm 1.23$ & $94.56 \pm 2.32$ & \multirow{2}{*}{$\begin{array}{c}\text { clear, slightly } \\
\text { yellow } \\
\text { solution }\end{array}$} & $5.5 \pm 0.00$ & $56 \pm 4$ \\
\hline & 6 months & $93.19 \pm 5.43$ & $96.58 \pm 0.01$ & $94.43 \pm 1.19$ & $93.60 \pm 1.11$ & & $6.0 \pm 0.00$ & $60 \pm 5$ \\
\hline \multirow[t]{2}{*}{$\mathrm{F} 4$} & initial & $99.00 \pm 3.44$ & $99.57 \pm 1.01$ & $96.87 \pm 0.65$ & $99.34 \pm 2.88$ & \multirow{2}{*}{$\begin{array}{c}\text { clear, slightly } \\
\text { yellow } \\
\text { solution }\end{array}$} & $5.5 \pm 0.01$ & $22 \pm 10$ \\
\hline & 6 months & $98.10 \pm 0.05$ & $97.15 \pm 1.15$ & $95.44 \pm 0.21$ & $98.69 \pm 3.21$ & & $5.8 \pm 0.02$ & $28 \pm 2$ \\
\hline \multirow[t]{2}{*}{ F5 } & initial & $98.26 \pm 0.24$ & $101.21 \pm 0.89$ & $95.49 \pm 0.23$ & $98.71 \pm 2.13$ & \multirow{2}{*}{$\begin{array}{c}\text { clear, slightly } \\
\text { yellow } \\
\text { solution }\end{array}$} & $5.5 \pm 0.00$ & $40 \pm 6$ \\
\hline & 6 months & $97.33 \pm 0.12$ & $99.40 \pm 2.11$ & $96.78 \pm 0.53$ & $98.44 \pm 1.00$ & & $5.8 \pm 0.02$ & $48 \pm 6$ \\
\hline \multirow[t]{2}{*}{ F6 } & initial & $95.49 \pm 3.12$ & $100.03 \pm 4.22$ & $94.32 \pm 3.89$ & $97.64 \pm 1.64$ & \multirow{2}{*}{$\begin{array}{c}\text { clear, slightly } \\
\text { yellow } \\
\text { solution }\end{array}$} & $5.5 \pm 0.00$ & $28 \pm 6$ \\
\hline & 6 months & $94.61 \pm 1.00$ & $99.78 \pm 2.22$ & $95.30 \pm 0.09$ & $95.19 \pm 1.10$ & & $5.9 \pm 0.02$ & $34 \pm 4$ \\
\hline \multirow[t]{2}{*}{ F7 } & initial & $98.73 \pm 2.12$ & $98.65 \pm 1.21$ & $98.18 \pm 2.06$ & $94.23 \pm 2.23$ & \multirow{2}{*}{$\begin{array}{c}\text { clear, slightly } \\
\text { yellow } \\
\text { solution }\end{array}$} & $5.6 \pm 0.01$ & $42 \pm 7$ \\
\hline & 6 months & $97.43 \pm 0.28$ & $96.66 \pm 0.34$ & $95.38 \pm 3.20$ & $95.10 \pm 2.12$ & & $5.7 \pm 0.01$ & $46 \pm 6$ \\
\hline \multirow[t]{2}{*}{ F8 } & initial & $94.16 \pm 0.55$ & $99.32 \pm 2.11$ & $95.91 \pm 1.32$ & $100.44 \pm 1.33$ & \multirow{2}{*}{$\begin{array}{c}\text { clear, slightly } \\
\text { yellow } \\
\text { solution }\end{array}$} & $5.5 \pm 0.00$ & $60 \pm 5$ \\
\hline & 6 months & $93.22 \pm 0.45$ & $98.65 \pm 2.12$ & $95.34 \pm 0.34$ & $99.64 \pm 1.98$ & & $5.9 \pm 0.00$ & $65 \pm 10$ \\
\hline
\end{tabular}

${ }^{\mathrm{a}} n=3$

range of 7.15-8.9 in some studies, the acidic $\mathrm{pH}$ solution showed healing property rates significantly higher than the basic $\mathrm{pH}$ solution $(20,23)$. The $\mathrm{pH}$ of all spray formulations was found in the range 5.5 to 6.0, which could produce healing efficacy.

The viscosity of all formulations was between 20 and $60 \mathrm{mPa}$ s, as shown in Fig. 3a. Formulations containing a high level of copovidone (6\%) and a high content of PEG 400 (10 \%) (formulations F3, F4, F7 and F8) had higher viscosity than those with low contents of polymers. These phenomena were pronounced for formulations containing a low content of ethanol ( $40 \%)$. This may have been a result of high solubility of the polymer in the solvent system, resulting in high viscosity.

As anticipated, the viscosity of $C$. asiatica extract-HP- $\beta$-CD complexed topical solutions was a function of copovidone concentration. When the concentration of copovidone increased, the viscosity of formulation increased. 
a)

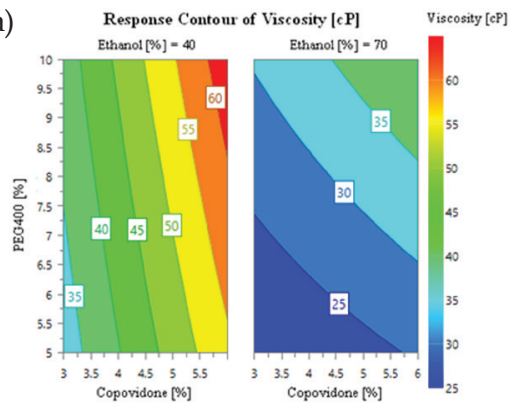

C) Response Contour of Surface tension $\left[\mathrm{mNN} / \mathrm{m}^{2}\right]$ Surfece tension $\left[\mathrm{mN} / \mathrm{m}^{2}\right]$

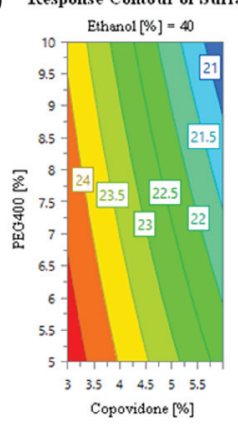

Ethanol $[\%]=70$

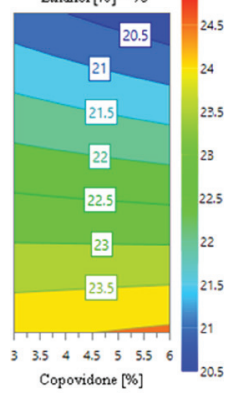

b)

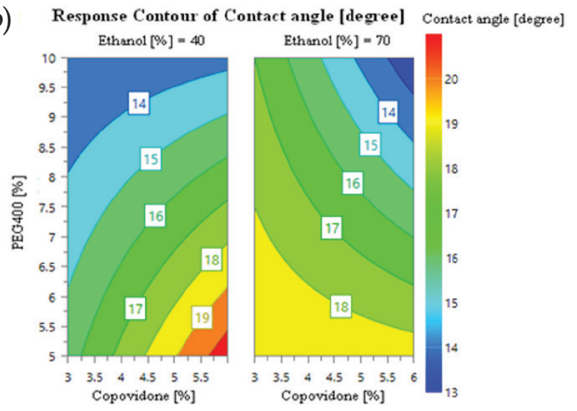

Fig. 3. a) Response contour of viscosity (cP), b) contact angle $\left(^{\circ}\right)$, and c) surface tension $\left(\mathrm{mN} \mathrm{m}^{-1}\right)$ of Centella asiatica extract-HP- $\beta$-CD topical spray (F1-F8) (mean $\pm \mathrm{SD}, n=3)$.

The formulations showed very low surface tension, indicating that the formulation could be spread well on the skin. The contact angle was also used to predict the spreadability of the formulation while applied onto the skin. If $\theta$ is less than $20^{\circ}$ the liquid tends to spread out over the surface and when the liquid forms a thin film, $\theta$ tends to zero (24). Contact angles of all formulations were $12.3-20.7^{\circ}$ (Fig. 3b), implying that all formulations could be easily spread on the skin. Surface tension was related to the spreadability of the formulation on the skin. Surface tensions of all formulations were between 20.3 and 24.6 $\mathrm{mN} \mathrm{m}^{-1}$ (Fig. 3c). The content of PEG 400, copovidone and ethanol slightly affected the surface tension of this system. All the formulations had similar results for surface tension, contact angle and appearance. The calculated spreadability $(S)$ of all formulations was about 10-20. A high content of PEG 400, copovidone and a low content of ethanol resulted in a high $S$ value. The high $S$ value indicated that the formulation had better spreadability. In addition, the evaporation time of all formulations, after being sprayed on paper, was less than 5 min (3.4-4.8 min).

Optimized formulations were chosen on the basis of physiochemical properties as well as satisfactory comments obtained from volunteers. The survey showed that the volunteers were satisfied and gave a 3-4 score (good to very good) to all formulations (F1-F8). In this study, we chose formulation F8 for the in vivo study due to its medium level of viscosity and the highest satisfactory score by the volunteers.

Physical stabilities of all formulations (F1-F8) are given in Table II. The physical properties (appearance, viscosity and $\mathrm{pH}$ ) were not changed upon storage at $30{ }^{\circ} \mathrm{C} / 75 \% \mathrm{RH}$ for 6 months. Analysis of triterpene contents calculated from equation 1 after storage at 30 


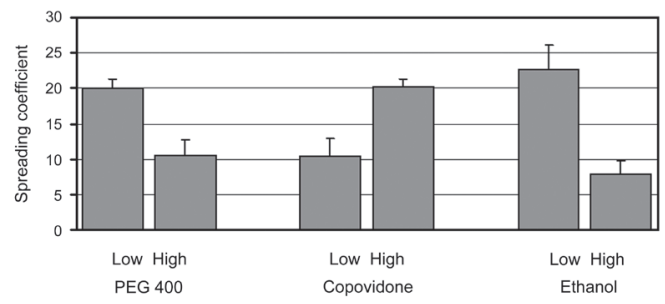

Fig. 4. The effect of PEG, copovidone and ethanol content on the spreading coefficient of Centella asiatica topical spray solution (mean $\pm \mathrm{SD}, n=6$ ).

${ }^{\circ} \mathrm{C} / 75 \%$ RH for 6 months confirmed that asiatic acid ranged from 93.19 to $98.10 \%$, madecassic acid from 94.33 to $99.78 \%$, asiaticoside from 92.12 to $96.78 \%$ while madecassoside was in the range of 93.60 to $99.64 \%$.

The $\mathrm{pH}$ of all formulations was 5.5-6.0, which was close to the $\mathrm{pH}$ of skin. The viscosity of all formulations was well within the range of $28-65 \mathrm{mPa} s$ which was slightly increased from the initial one. This may be a result of solvent evaporation during storage.

\section{Effects of PEG 400, copovidone and ethanol on spreadability}

$S$ values depended on the viscosity of the formulation. Surface tension and contact angle were affected by ethanol and PEG 400 contents (Fig. 4). Higher content of PEG 400 resulted in a lower $S$ value. In contrast, high level of copovidone showed high spreadability. The high content of ethanol in the formulation decreased the $S$ value.

\section{Skin irritation and efficacy of wound healing}

No erythema and/or edema were detected in the primary skin irritation studies of the selected formulation applied onto rat skin. Therefore the $C$. asiatica-HP- $\beta$-CD topical spray was found to be safe and nonirritant for topical application onto fresh wounds. As shown in Fig. 5, wound healing studies performed in 3 various groups revealed that there was significant wound healing in group 3 treated with $C$. asiatica extract compared to the control group (group 1). However, group 2 involving conventional wound treatment with povidone iodine solution showed the highest wound healing activity due to its antimicrobial activity. To improve the wound healing ability of $C$. asiatica, other antibacterial agents or some other natural products could be included to enhance the quality of formulations. Asiaticoside (see Fig. 2), a major constituent of the herb, is known to promote wound healing by reducing lipid peroxide levels in the wound (13). Several reports describe full contraction and recovery of the wound within 14 days in a hygienic environment $(9,26)$. The antibacterial action of $C$. asiatica extract containing asiaticoside contributes to the wound healing activity (27). Asiaticoside stimulates the epidermis by activating the malphigian layer cells and keratinization (27). Asiaticoside also promotes wound healing by increasing the tensile strength of the newly formed skin. The most important activity of asiaticoside is to promote the synthesis of collagen and acidic mucopolysaccharides and inhibit the inflammatory phase that causes hypertrophic scars and keloids (1). In addition, high content of ethanol (70 \%) may be sterilizing and may have synergistic effects with the product. 


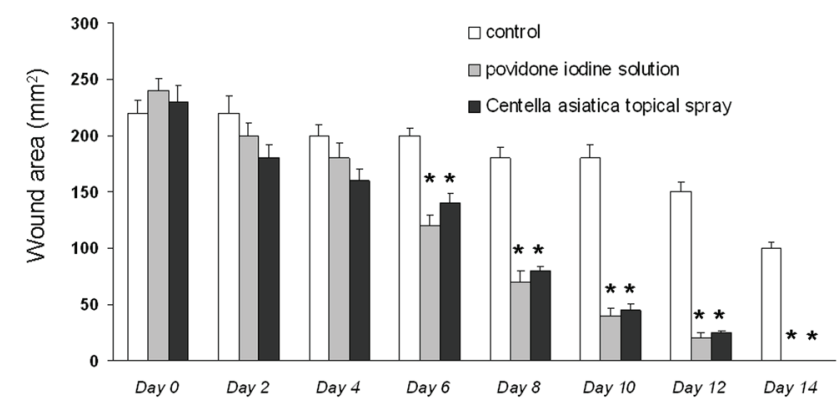

Fig. 5. Excision wound areas in rats (mean $\pm \mathrm{SD}, n=6) .{ }^{*} p$-value $<0.05$ compared to the control group.

\section{CONCLUSIONS}

Triterpene active compounds (asiatic acid, madecassic acid, madecassoside, asiaticoside) were found in C. asiatica extract. A spray containing $C$. asiatica extract complexed with $\mathrm{HP}-\beta$-CD was successfully developed for the treatment of fresh wounds. Physical evaluations showed acceptable appearance, $\mathrm{pH}$ and viscosity. The results indicated that formulations containing $6 \%$ of copovidone and $10 \%$ of PEG 400 had a high ability of being spread on the skin. All formulations showed good stability under stress and tropical storage conditions. The selected formulation (formula F8) showed high efficacy for the treatment of fresh wounds.

Acknowledgements. - The authors thankfully acknowledge the support rendered by the Drug and Cosmetics Research and Development Unit, Walailak University.

\section{REFERENCES}

1. D. Arora, M. Kumar and S. D. Dubey, Centella asiatica - a review of its medicinal uses and pharmacological effects, J. Nat. Remedies 2 (2002) 143-149.

2. K. J. Gohil, J. A. Patel and A. K. Gajjar, Pharmacological review on Centella asiatica: a potential herbal cure-all, Indian J. Pharm. Sci. 72 (2010) 546-556; DOI: 10.4103/0250-474X.78519.

3. P. Hashim, H. Sidek, M. H. M. Helen, A. Sabery, U. D. Palanisamy and M. Ilham, Triterpene composition and bioactivities of Centella asiatica, Molecules 16 (2011) 1310-1322; DOI: 10.3390/molecules16021310.

4. P. Puttarak and P. Panichayupakaranunt, Factor affecting the content of pentacyclic triterpenes in Centella asiatica raw materials, Pharm. Biol. 50 (2012) 1508-1512; DOI: 10.3109/13880209.2012.685946.

5. J. T. James and I. A. Dubery, Pentacyclic triterpenoids from the medicinal herb, Centella asiatica (L) urban, Molecules 14 (2009) 3922-3941; DOI: 10.3390/molecules14103922.

6. Y. Kuo, H. Chien and W. Lu, Plectranthus amboinicus and Centella asiatica cream for the treatment of diabetic foot ulcers. Evid. Based Complement. Alternat. Med. Article ID418649 (2012) 1-9; DOI: 10.1155/2012/418679.

7. N. A. Patel, M. Patel and R. P. Patel, Formulation and evaluation of polyherbal gel for wound healing. IRJP 1 (2011) 15-20.

8. M. E. Brewster and T. Loftsson, Cyclodextrins as pharmaceutical solubilizers, Adv. Drug Deliv. Rev. 59 (2007) 645-666; DOI: 10.1016/j.addr.2007.05.012. 
9. S. Nurdiana and N. Marziana, Wound healing activities of Melastoma malabathricum leaves extract in sprague dawley rats, Int. J. Pharm. Sci. Rev. Res. 20 (2013) 20-23.

10. G. Tejashi, B. Amrita and J. Darshana, Cyclodextrin based nanosponges for pharmaceutical use: A review, Acta Pharm. 63 (2013) 335-358; DOI: 102478/acph-2013-0021.

11. R. L. Carrier, L. A. Miller and I. Ahmed, The utility of cyclodextrins for enhancing oral bioavailability, J. Control. Release 123 (2007) 78-99; DOI: 10.1016/j.jconrel.2007.07.018.

12. J. Fan, R. Zhang, X. Zhang, J. Zhu and J. Huang, Separation of three triterpene acids in leaves of Diospyros kaki by high performance liquid chromatography using hydroxypropyl- $\beta$-cyclodextrin as mobile phase modifier, J. Liq. Chromatogr. R. T. 34 (2011) 1340-1355; DOI: 10.1080/10826076.2011.570841.

13. N. S. Jagtap, S. S. Khadabadi, I. A. Farooqui, V. P. Nalamwar and H. A. Sawarka, Development and evaluation of herbal wound healing formulations, Int. J. PharmTech Res. 1 (2009) 1104-1108.

14. K. N. Han, Chapter 1 Interfacial Phenomena, Fundamentals of Aqueous Metallurgy, Society for Mining, Metallurgy and Exploration Inc., USA, 2009, pp. 16-18.

15. N. Pawer and H. Chaudhary, Non-pressurized topical spray of diclofenac diethylamine. International Journal of Advances in Pharmaceutics 4 (2015) 40-48; DOI: 10.7439/ijap.

16. B. T. Schaneberg, J. R. Mikell, E. Bedir and I. A. Khan, An improved HPLC method for quantitative determination of six triterpenes in Centella asiatica extracts and commercial products, Pharmazie 58 (2003) 381-384.

17. B. Günther and H. Wagner, Quantitative determination of triterpenes in extracts and phytopreparations of Centella asiatica (L.) Urban, Phytomedicine 3 (1996) 59-65; DOI: 10.1016/S0944-7113(96)800110 .

18. R. K. Verma, K. G. Bhartariya, M. M. Gupta and S. Kumar, Reverse-phase high performance liquid chromatography of asiaticoside in Centella asiatica, Phytochem. Anal. 10 (1999) 191-193; DOI: 10.1002/ (SICI)1099-1565(199907/08)10:4<191::AID-PCA456>3.0.CO;2-R.

19. N. A. Zainol, S. C. Voo, M. R. Sarmidi and R. A. Aziz, Profiling of Centella asiatica (L.) Urban extract, Malaysian J. Anal. Sci. 12 (2008) 322-327.

20. L. A. Schneider, A. Korber, S. Grabbe and J. Dissemond, Infuence of pH on wound-healing: a new perspective for wound-therapy?, Arch. Dermatol. Res. 298 (2007) 413-420; DOI: 10.1007/s00403-0060713-x.

21. H. Lambers, S. Piessens, A. Bloem, H. Pronk and P. Finkel, Natural skin surface pH is on average below 5, which is beneficial for its resident flora, Int. J. Cosmet. Sci. 28 (2006) 359-370; DOI: 10.1111/ j1467-2494.2006.00344.5.

22. Y. C. Woo, S. S. Park, A. R. Subieta and T. J. Brennan, Changes in tissue pH and temperature after incision indicate acidosis may contribute to postoperative pain, Anesthesiology 101 (2004) 468-475.

23. S. L. Percival, S. McCarthy, J. A. Hunt and E. J. Woods, The effects of pH on wound healing, biofilms, and antimicrobial efficacy, Wound Rep. Reg. 22 (2014) 174-186; DOI: 10.1111/wrr.12125.

24. C. Lens, J. J. Lucchini and P. Grascha, A scientific study that proves alcohol hand sanitiser is more efficacious when dispensed onto the hands as foam rather than as gel, Can. J. Infect. Control 26 (2011) 21-25.

25. H. S. Grewal, H. N. Kim, I. Cho and E. Yoon, Role of viscous dissipative processes on the wetting of textured surfaces, Scientific Reports 5 (2015) 14159 1-11; DOI: 10.1038/srep14159.

26. J. E. Janis, R. K. Kwon and D. H. Lalonde, A practical guide to wound healing, Plast. Reconstr. Surg. 125 (2010) 230-244; DOI: 10.1097/PRS.0b013e3181d9a0d1.

27. V. Seevaratnam, P. Banumathi, M. R. Premalatha, S. P. Sundaram and T. Arumugam, Functional properties of Centella asiatica (L.): a review, Int. J. Pharm. Pharm. Sci. 4 (2012) 8-14. 